Article

\title{
Research on NEV Platform Development Strategies for Automotive Companies
}

\author{
Zongwei Liu ${ }^{1,2}$, Xinglong Liu ${ }^{1,2}$ and Fuquan Zhao ${ }^{1,2, *}$ \\ 1 State Key Laboratory of Automotive Safety and Energy, Tsinghua University, Beijing 100084, China; \\ liuzongwei@tsinghua.edu.cn (Z.L.); 1x119@mails.tsinghua.edu.cn (X.L.) \\ 2 Tsinghua Automotive Strategy Research Institute, Tsinghua University, Beijing 100084, China \\ * Correspondence: zhaofuquan@tsinghua.edu.cn; Tel.: +86-10-62797400
}

check for updates

Citation: Liu, Z.; Liu, X.; Zhao, F. Research on NEV Platform Development Strategies for Automotive Companies. World Electr. Veh. J. 2021, 12, 201. https://doi.org/ 10.3390/wevj12040201

Academic Editors: Kai Liu, Jiangbo Wang and Wei Fan

Received: 27 September 2021

Accepted: 18 October 2021

Published: 19 October 2021

Publisher's Note: MDPI stays neutral with regard to jurisdictional claims in published maps and institutional affiliations.

Copyright: (c) 2021 by the authors. Licensee MDPI, Basel, Switzerland. This article is an open access article distributed under the terms and conditions of the Creative Commons Attribution (CC BY) license (https:/ / creativecommons.org/licenses/by/ $4.0 /)$.

\begin{abstract}
Developing new energy vehicles (NEVs) is essential for China's automotive industry to achieve carbon peak and carbon neutrality goals. The development of a NEV platform is an effective means for automotive companies to balance the development cost, development time, and product performance of NEVs. However, there is no clear solution to choosing new energy vehicle platform development strategies and models for automotive companies. This paper mainly studies the significance of NEV platform development, the classification and characteristics of NEV platforms, and the development strategies and trends of NEV platforms for automotive companies. The study results found that choosing a new dedicated electric platform (NDEP) is inevitable for the latest automotive companies, such as TESLA Motors. An adapted electric platform (AEP) is a temporary solution that meets the dual credits policy. It lacks competitiveness and has been gradually eliminated for the traditional automotive companies. The new dedicated electric platform is a longterm development solution when comprehensively considering the market, technology, and policy. The compatible platform $(\mathrm{CP})$ is a transitional solution when considering the development trend of automotive powertrain, the market size of NEVs, and the platform technology of NEVs. Besides, joint development and shared use is the primary development model for the automotive enterprise in the future. Finally, companies should increase their research and development efforts on NEV architecture platforms to maximize platform-based development's scale effect and application value. The research can provide strategic guidance for automotive companies to develop NEV platforms.
\end{abstract}

Keywords: new energy vehicles; automotive enterprise; NEV platforms; development strategy

\section{Introduction}

China aims to achieve its carbon peak by 2030 and carbon neutrality by 2060 [1]. This poses severe challenges to China's automotive industry and brings specific development opportunities simultaneously [2]. The development of energy-saving and new energy vehicles (NEVs) is crucial for achieving carbon peak and carbon neutrality goals for China's automotive industry, especially NEVs [3,4]. The NEVs investigated in this study included plug-in hybrid vehicles (PHEVs), extended-range electric vehicles (EREVs), and BEVs (BEVs) [5]. According to the latest data from the China Association of Automotive Manufacturers (CAAM), the penetration rate of NEVs in China has reached 15\% in July 2021 [6]. China's strong support for NEVs and the rapid increase in the size of the NEV market have driven the rapid transformation of vehicle electrification globally [7]. The automotive companies have gradually increased their research and development efforts on NEVs worldwide. The current challenges in promoting NEVs are mainly due to the high initial purchase cost, mileage anxiety, and poor charging infrastructure [8,9]. Even though the cost of power batteries has been reduced gradually, the price of manufacturing vehicles is still relatively high compared with traditional internal combustion engine vehicles (ICEVs) [10]. It will bring specific challenges to the profitability of automotive companies. At the same time, the rapid development of the automotive industry requires automotive companies to 
respond to the complex and changeable market on time and launch competitive automotive products within a limited time. Therefore, effectively balancing the production cost, development time, and automotive product performance (range) of NEVs is crucial for automotive companies to develop.

Many factors affect the profitability of automobile companies in the new world competition landscape, such as the digital technological revolution, scientific enterprise management, and platform-based development models [11-14]. Platform-based development can fully play the cost-saving advantages brought by large-scale manufacturing [15-17]. The platform-based development model has received extensive attention and application in the automotive industry. Moreno et al. analyzed the introduction of a platform strategy in new product development concerning its application in the automotive enterprise. A definition of platform and associated core concepts such as product architecture, modularization, and standardization are given. The implication and benefits of a platform strategy are then discussed both from the technical and organizational points of view. The results concluded that the introduction of a platform strategy affects firms' performances [18]. Hodges et al. studied the issues in automotive product platform strategies. They concluded that key automotive platform issues include economies of scale and potential loss of brand differentiation. They only summarized some observations and questions about platform strategies. They did not give solutions for automotive companies to select product strategies [19]. Zhao et al. conducted a study to analyze the development model and implementation strategy of an automotive product platform and modularity. They concluded that an automotive platform can shorten the development time of automotive products. The core of platform development is to realize the common use of parts between different products, emphasizing some fixed parts combinations within the same platform [20]. However, the focus is on the ICEV's traditional platforms from an automotive industry platform perspective [21]. The literature review concerning NEV platforms revealed little research explicitly addressing this phenomenon. The NEVs are more sensitive to cost, development time, and product performance [22]. When the development trend of NEVs is irreversible, the development of NEV platforms has become an effective means for automotive companies to save research and development costs and improve market competitiveness. Therefore, it is necessary to conduct a comprehensive study on the new energy vehicle platform on the basis of the traditional vehicle platform.

According to the research and judgment of our research group, the era of automotive power 2.0 is coming, and the automotive industry is rapidly entering the age of diversified powertrains [23]. It will be the long-term coexistence of internal combustion engine vehicles (ICE), hybrid electric vehicles (HEV), plug-in hybrid electric vehicles (PHEV), extended-range electric vehicles (REV), battery electric vehicles (BEV), and fuel cell vehicles (FCEV) [24,25]. They will hold different market shares and change gradually over time. In the long run, NEVs are the future development direction. The development of an NEV platform is an inevitable choice for automotive companies. However, there is uncertainty about the development of automotive powertrains in the short term. It is critical for automotive companies to develop a platform that considers all powertrains based on traditional platforms or to redevelop a platform that only applies to BEVs. Therefore, the choice of the NEV platform development strategy needs to weigh the relationship with the traditional platform. NEVs are very different from traditional vehicles in powertrain, structural layout, and safety requirements [26]. NEVs need to redevelop the vehicle platform to fully play their performance advantages such as electric range [22]. Therefore, developing a NEV platform is not a necessary an option when considering enterprise development costs and platform development capabilities. It is why most companies use the adapted electric platform to launch new energy vehicle products at the beginning [27]. Therefore, they also need to consider balancing the relationship between platform development costs and product performance when companies develop NEV platforms.

The development strategies of NEV platforms for automotive companies are relatively complicated. They need to be studied systematically and urgently. At present, there are 
relatively little studies on NEV platforms. Sergio et al. presented and discussed two distinct electric vehicle platform strategies [22]. They analyzed the platform development models of Ford Motors and Volkswagen Motors and explained the differences between the two platforms. However, the classification of platforms in their study is not comprehensive, and it fails to cover all NEV platforms. This study does not systematically analyze the selection strategy and development model of the NEV platforms.

Based on the above analysis, the current researches on new energy vehicle platforms have the following research questions:

(1) What is the significance of the development of new energy vehicle platforms by automotive companies?

(2) What are the types and characteristics of new energy vehicle platforms?

(3) How do automotive companies choose their new energy vehicle platforms' development strategy and development model?

To fill these gaps, this study has researched the development strategy of new energy vehicle enterprise platforms. The structure of the article is structured as follows. Section 1 introduces the background of NEV platform development and current research problems. Section 2 describes the importance of automotive companies in developing NEV platforms. The classification and characteristics of NEV platforms are discussed in Section 3. The selection strategy, development model, and development trends of automotive companies for the development of NEV platforms are investigated in Section 4. Section 5 summarizes this study and give some suggestion for automotive companies to develop the NEV platforms.

\section{Significance and Progress of NEV Platform Development}

The significance of developing a NEV platform for automotive companies is summarized [28-30]. It mainly includes three aspects as follows.

Firstly, the development of a NEV platform can reduce the production cost of automotive products, shorten the development cycle of automotive products, and lower the risk of automotive products. It is also the significance of traditional vehicle platform development. Similarly, it is more significant for NEVs. Due to the existence of power batteries, the production cost of NEVs is higher than that of traditional ICEVs. Therefore, it is of great significance for the large-scale promotion of NEVs to reduce the platform development of production costs before the qualitative change of battery technology. Besides, consumers have higher requirements for the iterative upgrading of automotive products in the wave of electrification. Platform-based development can reduce validation time and shorten development cycles. It enables automotive companies to develop multiple products and quickly bring them to market, thus significantly improving their competitiveness. Moreover, platform-based development can increase the use of common parts and reduce quality issues. It can decrease development risks and enhance the quality of new energy vehicle products.

Secondly, the NEV platform can guarantee the product performance of NEVs and improve product competitiveness. There are significant differences between NEVs and traditional vehicles in powertrain, structure layout, and safety requirements. For example, NEVs have relatively large battery packs. That requires a unique design for better performance. Platform development can be designed according to the characteristics of NEVs, to give full play to their performance advantages [31]. These advantages are mainly reflected as follows. The NEV platform is conducive to optimizing the space. For example, the electric drive system is smaller than an ICE powertrain. Therefore, the suspension design can be reduced. The wheelbase can be increased, and the passenger space can be optimized using the creation of the NEV platform. Besides, the NEV platform can be designed in coordination with the battery pack to maximize the safety of the body structure.

Meanwhile, the NEV platform can achieve a balanced bodyweight according to the characteristics of electric vehicles. For example, Guangzhou Automobile Group (GAC) GEP2.0 NDEP can achieve a vehicle front and rear ratio close to 50:50, which would effectively improve the vehicle handling stability [32]. 
Thirdly, the development of the NEV platform is the accumulation of technology for automotive companies. It is conducive to the upgrading and expansion of the following platforms. Although the diversification of vehicle power 2.0 is widespread, the general trend of electric transformation of vehicle power will not be reversed [23]. Therefore, the development of the NEV platform can accumulate technology for the upgrading of the new dedicated electric platform and the development of hydrogen fuel cell electric vehicle platforms in the future.

At present, automotive companies have fully realized the significance of the NEV platform's development worldwide. Various companies are increasing their research and development efforts on NEV platforms. At present, there are two main modes for automotive companies to develop NEV platforms. The first is creating a NEV platform that produces only battery electric vehicles such as the Volkswagen MEB platform and Guangzhou Automobile Group (GAC) GEP2.0 platform [32,33]. The other is to develop a new energy platform that can produce different powertrain (HEV, PHEV, BEV) such as Jaguar Land Rover MLA platform [34]. At present, the industry is still in the early stage of NEVs, and various companies have different understandings of NEV platforms. There is no precise classification of NEV platforms in the industry now. It is necessary to systematically sort out the types and characteristics of NEV platforms from an academic perspective.

\section{Analysis of Types and Characteristics of NEV Platforms}

According to the University of Michigan Transportation Research Institute (UMTRI), the platform types of NEVs can be defined from two dimensions of platform strategy and design ideas [35]. The current NEV platform strategy includes the adapted electric platform (AEP) and the new electric platform (NEP). The design idea contains adapted electric vehicle design (AEVD) and new electric vehicle concept design (NEVD) according to the degree of transformation design. The NEV platform can be defined into three types according to the definition. They are adapted electric platform (AEP), compatible platform $(\mathrm{CP})$, and new dedicated electric platform (NDEP), as shown in Figure 1.

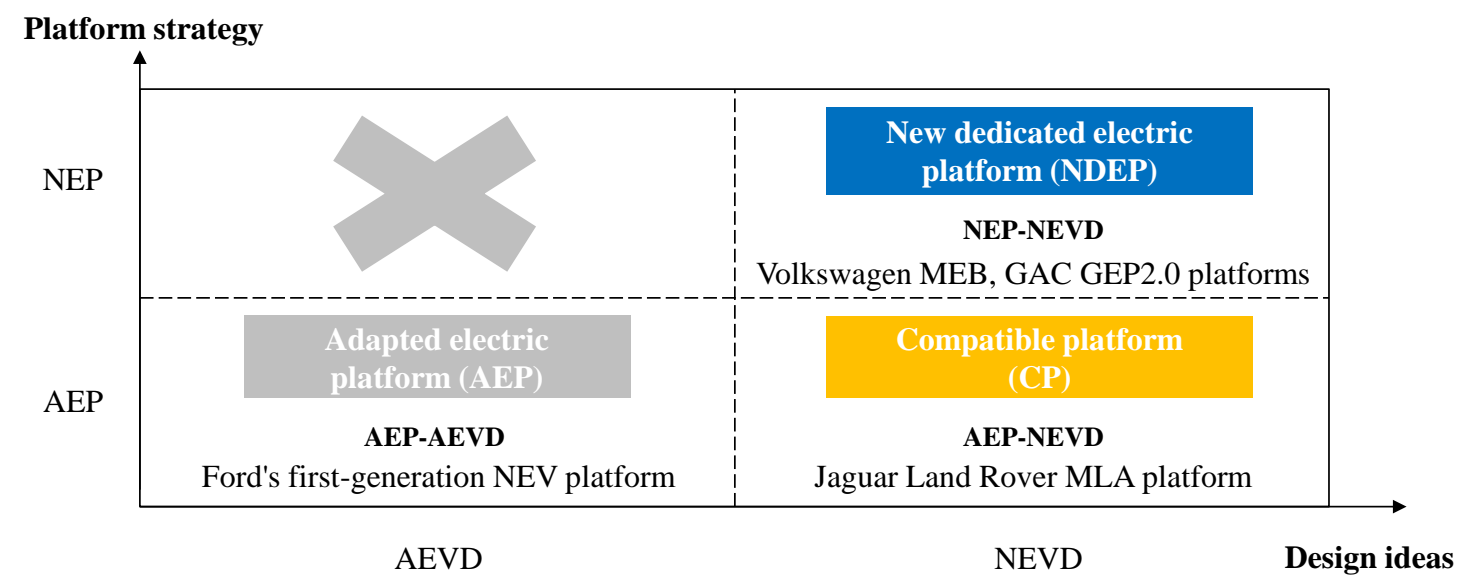

Figure 1. Platform types of NEVs.

The adapted electric platform is essentially underpinning the EVs on the same ICEV platform. It has the advantage of being compatible with a variety of powertrain solutions. On the other hand, the platform can share components from traditional ICEV platforms. Therefore, it is a short-term solution for the automotive companies to enter the new energy vehicle market at a low cost, but it will limit the performance of NEVs, especially the driving range of battery electric vehicles. The first generation of NEV platforms for Ford Motor is the adapted electric platform [27].

The compatible platform is a new design based on the traditional ICEV platform [36]. It has considered the technical characteristics of various powertrains in the early stage of development. Therefore, it can exert the performance characteristics of NEVs as much as 
possible based on traditional ICEV platforms. The main difference between the compatible platform and the adapted electric platform is that the compatible platform is designed for multiple powertrains in mind in the early design stage. On the contrary, the adapted electric platform is intended for the ICEVs early and does some simple renovation design. At present, most compatible platforms can develop and produce different types of products, such as ICEVs, HEVs, PHEVs, and BEVs. BMW CLAR platform is a typical compatible platform [37]. It can consider the development of ICEVs, $48 \mathrm{~V}$ mild hybrid vehicles, PHEVs, and BEVs.

The new dedicated electric platform is a platform designed only for BEVs. It focuses more on BEVs' range and dynamic and consumer comfort. However, the commonality of parts and components of a new dedicated platform for BEVs is usually scarce or null. So, it is with limited economies of scale and scope. The Volkswagen MEB platform is a typical new dedicated platform for BEVs [33]. The MEB platform jettisons all the ballast of the fossil age as it has been designed consistently for electric cars. It leads to fundamental changes in body design, interior design, the package, and the powertrain characteristics of electric Volkswagens. A comparative analysis of the features of the three types of NEV platforms is shown in Table 1.

Table 1. Comparative analysis of characteristics of NEV platforms.

\begin{tabular}{cccc}
\hline Platform Type & Adapted Electric Platform & Compatible Platform & New Dedicated Platform for BEVs \\
\hline Definition & $\begin{array}{c}\text { Underpinning the EVs on the same } \\
\text { ICEV platforms }\end{array}$ & $\begin{array}{c}\text { A new design platform based on the } \\
\text { traditional ICEV platform }\end{array}$ & A platform designed explicitly for BEVs \\
Advantages & $\begin{array}{c}\text { Low R\&D cost; short development } \\
\text { cycle; can reach high economies of } \\
\text { scale and scope }\end{array}$ & $\begin{array}{c}\text { Can reach high economies of scale and } \\
\text { scope; product performance is better than } \\
\text { the production from AEP; powertrain type } \\
\text { covers an extensive range }\end{array}$ & $\begin{array}{c}\text { Performance can be optimized; in line with } \\
\text { the development direction of electric vehicles; } \\
\text { easier to combine with intelligent connected } \\
\text { vehicles [38,39] }\end{array}$ \\
\hline Disadvantages & $\begin{array}{c}\text { Poor performance of electric } \\
\text { vehicles such as limited electric } \\
\text { range of a vehicles }\end{array}$ & $\begin{array}{c}\text { Insufficient on the ICEVs, redundancy on } \\
\text { the BEVs, the product performance cannot } \\
\text { be maximized }\end{array}$ & $\begin{array}{c}\text { Small powertrain type coverage; long } \\
\text { development cycle; enormous investment; } \\
\text { limited economies of scale and scope }\end{array}$ \\
\hline
\end{tabular}

It is known that the adapted electric platform has the advantages of short research and development (R\&D) cycles and quick entry into the market with minimum $R \& D$ costs. Therefore, some automotive companies in China use adapted electric platforms in the early stage of developing NEVs. It enables automotive companies to enter the market of NEVs at the lowest cost quickly. However, the NEVs created using the adapted electric platform have to adapt to the limitations of traditional platforms and cannot fully exploit the performance of NEVs. Therefore, some companies will carry on the new design to the traditional ICEV platform, considering the characteristics of various powertrains in the early stage of development. This is often called a compatible platform. The product performance manufactured from a compatible platform is better than that of the adapted electric platform, which can give play to the advantages of NEVs to a certain extent. However, a compatible platform is to take into account the development of a variety of powertrains after all. Performance is not optimal for different powertrains. A new dedicated electric platform is explicitly designed for the performance characteristics of BEVs. It can give full play to the performance of BEVs. However, it has a long development cycle and high research and development costs. If the sales volume of BEVs is not large enough, it will bring investment risks for automotive companies.

Therefore, developing a new dedicated electric platform is undoubtedly a gamble for automotive companies based on cost considerations. It is an excellent choice to introduce new energy products rapidly with lower cost by using an adapted electric platform in a scenario where the outlook for NEVs is not very clear. For example, Volkswagen used the existing MQB modular platform to derive many PHEV and BEV models to quickly enter the new energy vehicle market before the mass launch of MEB platform products. In addition, the performance of BEVs developed based on compatible platforms is not optimal. It is better than that produced from the adapted electric platform. The investment risk of compatible platforms is lower than that of a new dedicated electric platform. It 
enables companies to improve product competitiveness through relatively low costs. It can ensure that the automotive enterprise achieves profitability under the policy requirements.

\section{Research on NEV Platform Development Strategies for Automotive Companies}

\subsection{Research on NEV Platform Selection Strategy for Automotive Companies}

Automotive companies need to combine their external and internal factors when developing NEV platforms, as shown in Figure 2. The external factors mainly include policy trends, market scale, and technology development. The internal factors mainly include automotive enterprise type, future development strategies, and current technological reserves. External factors affect the development trend of the NEV platform, while internal factors determine the specific choice of the enterprise.

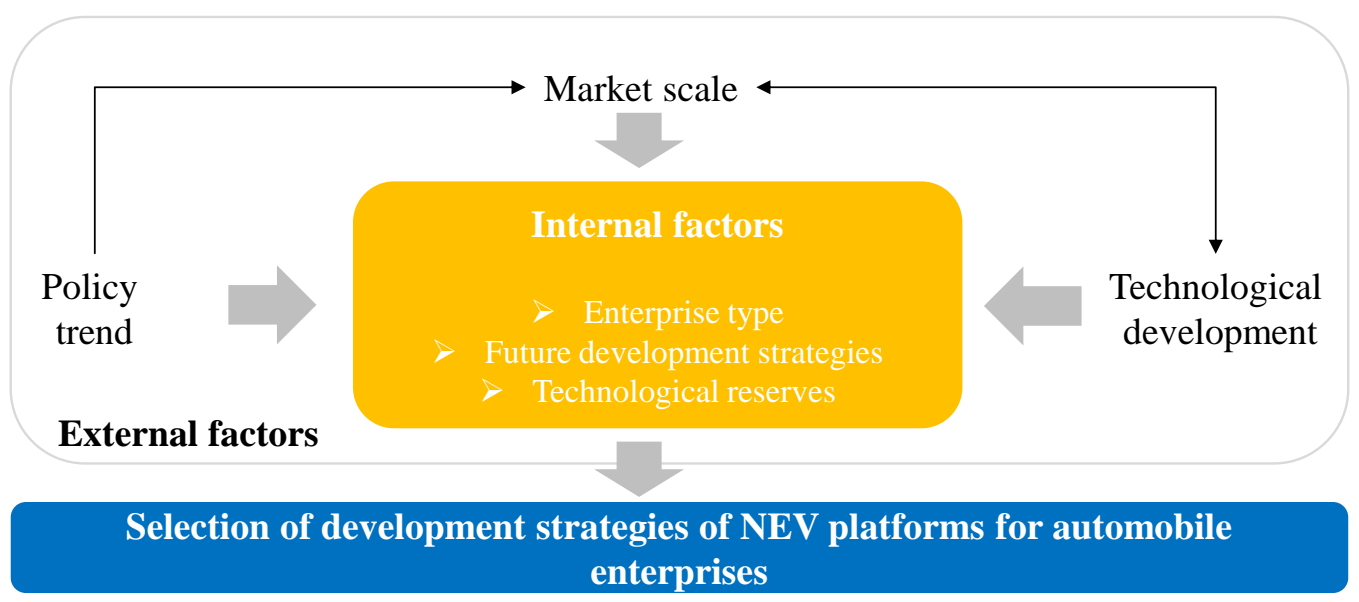

Figure 2. Factors influencing automotive companies' selection of development strategies for NEV platforms.

The platform selection strategy of NEVs based on external factors is shown in Figure 3. First of all, the dual credits policy requires automotive companies to produce a certain number of NEVs $[40,41]$. No matter which kind of NEV platform is adopted, NEVs can meet the policy requirements. Therefore, to meet the policy requirements, it can develop lower-cost platforms such as adapted electric platforms or compatible platforms in the short term. Adapted electric platforms and compatible platforms cannot give full play to the performance of battery electric vehicles, but they can be used as short-term choices to meet policy requirements. In the long run, companies should consider developing a new dedicated electric platform for BEVs. That could meet the dual credits policy and make the technology accumulation for the development of high-performance BEV simultaneously.

Influence of external factors such as policy, technology and market on the decision-making of NEV platforms

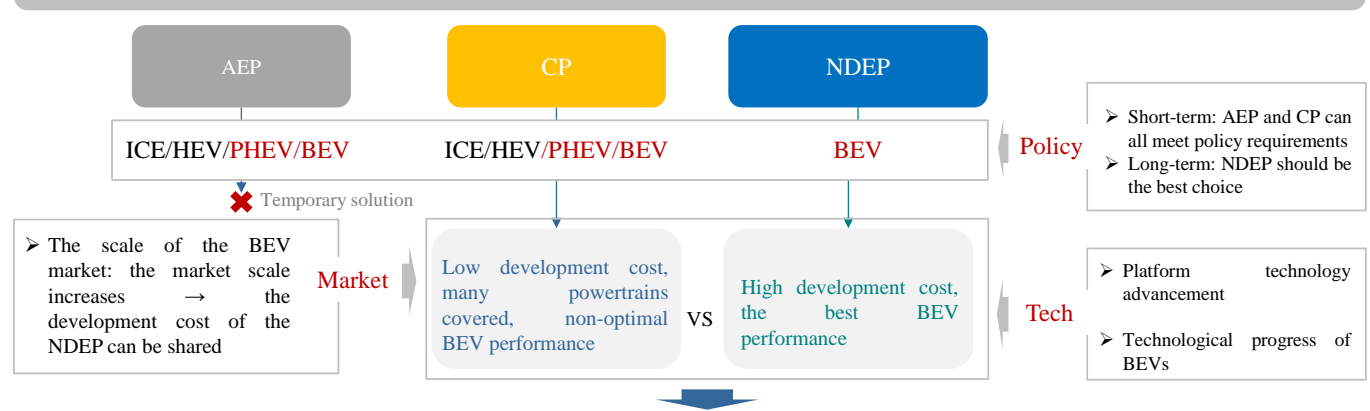

Judgment: AEP is a temporary solution; CP is a transition solution; NDEP is a long-term development solution

Figure 3. NEV platform selection strategy based on external factors. 
Secondly, technological development can be divided into two aspects: NEV platform technology and BEV technology. With the progress of platform technology, the gap between the R\&D cost of a new dedicated electric platform and a compatible platform is gradually narrowing. The performance of BEVs developed based on the new dedicated electric platform is the best. Therefore, automotive companies will choose the new dedicated electric platform. Besides, with technological progress such as battery technologies, the cost performance of BEVs will be lower than that of other powertrain vehicles from the life cycle perspective. Then the BEVs will become the mainstream automotive technology route in the future. It makes little sense for automotive companies to develop compatible platforms.

Finally, it can be seen that the current market share of NEVs is still tiny. It cannot make the NEV platform reach high economics of scale and scope and produce obvious economic benefits. Therefore, automotive companies mostly choose adapted electric platforms and compatible platforms to reduce the development cost of the platform in the current stage. However, with the increase of sales of NEVs, the development cost of the new dedicated electric platform can be amortized. Then automotive companies will give priority to the development of a new dedicated electric platform. For example, Jaguar Land Rover (JLR) has considered ditching compatible platforms (MLA platforms) in favor of a new dedicated electric platform [42,43].

In a word, the platform selection strategy of NEVs based on external factors can be obtained according to the abovementioned analysis. An adapted electric platform is a temporary solution with poor competitiveness. It will gradually be abandoned by mainstream automotive companies with the NEV market scale and technical progress. The compatible platform is a transitional solution when considering the development trend of automotive powertrain, the market size of NEVs, and the platform technology of NEVs. The new dedicated electric platform is a long-term development plan from the market, technology, and policy perspective. In this process, it is necessary to consider the switching time of a compatible platform to a new dedicated electric platform. If switching is too early, the benefits of a compatible platform are compromised. However, if the switch is too late, the performance of BEVs will be affected so that the market competitiveness will decrease at the same time.

Therefore, it is necessary for automotive companies to comprehensively evaluate the development strategy of the automotive platform based on internal factors that affect the development strategy of the NEV platform. It mainly includes enterprise type, enterprise development plan, and enterprise technology reserve.

Enterprise type. New automotive companies are developed entirely from scratch, with no sunk costs, such as Tesla Motors. It could simply choose to develop a new dedicated electric platform. In contrast, traditional automotive companies have long-term accumulation in traditional automotive technology. It can consider developing a compatible platform to give play to its technological advantages and enterprise accumulation. It may also consider developing a new dedicated electric platform simultaneously to maximize the performance of BEVs. For example, while developing compatible platforms (EVA platform), Daimler has also developed a new dedicated electric platform (MEA platform). Which platform development strategies to choose specifically, automotive companies need to combine their development strategies and technical reserves, as shown in Figure 4.

Automotive enterprise development strategies. The development strategies of automotive companies have a more significant impact on the choice of NEV platforms. Some automotive companies are full of confidence in the development of BEVs technical route, believing that it can become the market's mainstream in the next few decades. Therefore, these companies will prefer to develop a new dedicated electric platform, such as Volkswagen Motors. However, some companies do not recognize the technical development potential of BEVs. It will choose that developing a compatible platform that can consider multiple powertrains. To ensure that the enterprise meets the policy requirements and achieves a sure profit. For example, Bavarian Motor Works' (BMW's) attitude towards the 
technical development of BEVs is still unclear. It still plans to launch a new version of the CLAR platform in 2021, which can be compatible with various powertrain systems.

\section{Selection strategies of NEV platforms for traditional automotive enterprises}

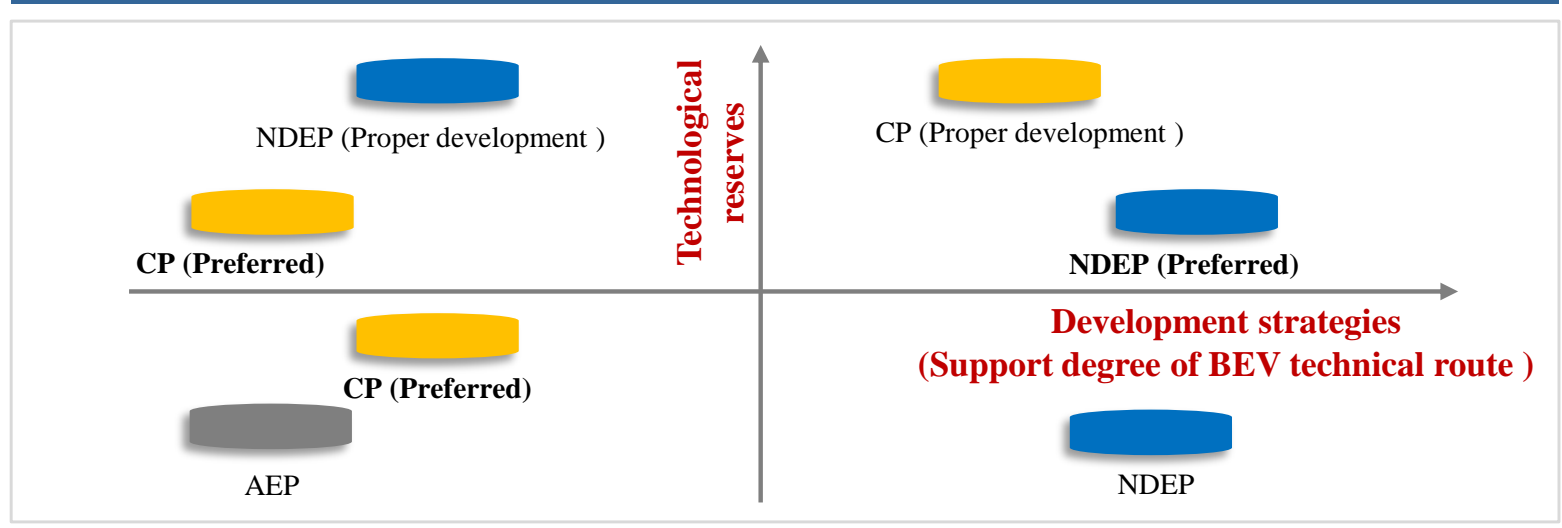

Figure 4. NEV platform selection strategy of traditional companies.

Automotive enterprise technology reserve. The technical reserves of automotive companies include technology accumulation and capacity scale. If the companies' technical reserves and production capacity are relatively high, they can develop a new dedicated electric platform for BEVs. Moreover, they can share the development cost of a new dedicated electric platform with a larger capacity scale. Of course, suppose a company has a relatively deep technical reserve on the traditional platform. In that case, it can also develop a compatible platform to give play to its own enterprise's advantages and increase profits.

Therefore, when an enterprise develops a NEV platform, it must consider external and internal factors. It is noted that compatible platforms and the new dedicated electric platform are mutually complementary for traditional automotive companies. The specific development strategy should be comprehensively evaluated according to the companies' development strategy and technical reserves. For example, automotive companies can develop compatible platforms in the short term to maintain profitability but do an exemplary job researching and developing the new dedicated platforms in the long term. In addition, some traditional companies can also develop compatible platforms and new dedicated platforms simultaneously. It will improve the performance of the company's BEVs while meeting market needs. However, developing a compatible platform and new dedicated electric platform simultaneously faces high development costs, so it is also necessary to choose a suitable development strategy.

\subsection{Research on the Development Model of NEV Platform for Automotive Companies}

At present, the development model of NEV platforms for automotive companies mainly includes an independent development model and a cooperative development model.

The independent development model is suitable for international brands with comprehensive strengths such as capital, technology, brand, and domestic first-line emerging automotive companies. The purpose is to improve the competitiveness of the enterprise's products through independent research and development. The scale effect is the core of the advantages for the automotive platform. Therefore, an enterprise with mature platform technology can share it with other companies [44,45]. It should be noted that the platform sharing of automotive companies needs to ensure that it has little impact on their brands. Through sharing, platforms and products' recognition and brand influence can be further improved. The R\&D and supply chain costs can be further amortized. It will 
increase the companies' brand premium and comprehensive competitiveness. For example, Volkswagen shares the MEB platform with Ford.

In addition, the companies with weaker overall strengths should give up the independent development of a new dedicated electric platform. It can enable automotive companies to avoid significant capital investments. These automotive companies should take the initiative to develop the new dedicated electric platforms with others jointly [46]. Or it can directly use others' mature platforms to produce their products. Of course, directly using the platforms of other companies will impede their product design. An automotive company should pay attention to the design of its products, to achieve the best product performance as much as possible when using the platforms of another enterprise. It should be noted that the differentiated design of platform products must be done when the new dedicated electric platform is in joint development or cooperative sharing. It can avoid the homogeneity problem of automotive products, which consumers dislike.

Independent or cooperative and shared development is the primary mode for current automotive companies to develop NEV platforms. The specific choice of development mode requires automotive companies to comprehensively consider various factors such as their brand, product market positioning, technology status and strength.

\subsection{Future Development Trend of NEV Platform for Automotive Companies}

The development of NEV platforms will be deeply tied to the change of automotive powertrains. The compatible platform is a transitional solution. The new dedicated electric platform is a long-term solution in the future when considering policy, technological development, and the scale of the new energy vehicle market. With the increase of the proportion of NEVs in the future, the NEV platform will be significant [47]. That is the development trend of NEV platforms for automotive companies in the future, as shown in Figure 5. Firstly, the adapted electric platform is a temporary solution. It expected that some weaker companies will have to adapt to meet policy requirements and quickly enter the new energy vehicle market. With the intensified competition in the BEV market and stricter policies, the adapted electric platform started to be phased out in 2020.

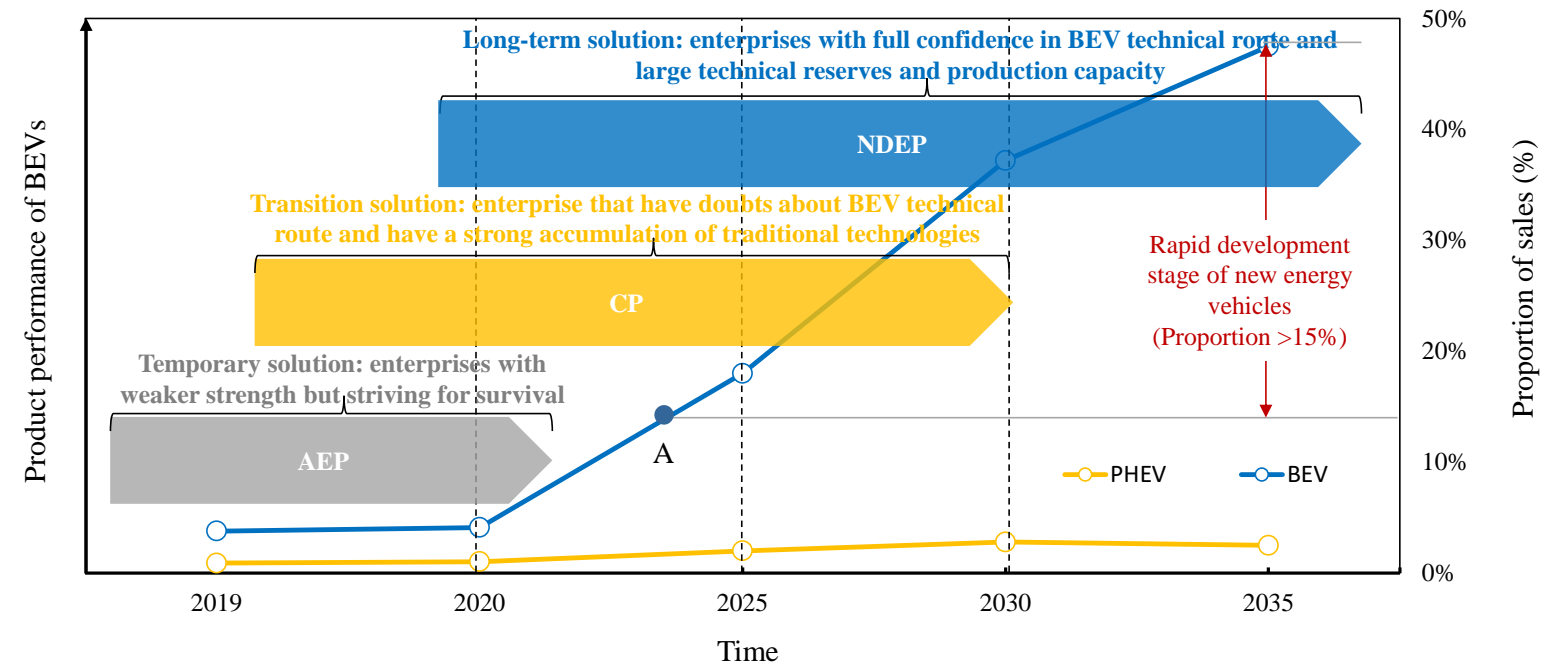

Figure 5. Development trend of NEV platform.

Second, some traditional companies have already developed compatible platforms to produce BEVs before 2020. On the one hand, they want to use the enterprise's accumulation of traditional technologies to increase sales and profitability by considering the production of other powertrains. On the other hand, developing a compatible platform can develop BEVs at a relatively low cost, thereby avoiding excessive capital investment and reducing investment risks. In the future, the new energy vehicle industry will develop further. In particular, the market share of battery electric vehicles will increase substantially. 
Compatible platforms cannot give full play to the performance of BEVs and cannot achieve real innovation. This will affect the enterprise's market sales of BEVs. Up to 2035, PHEVs will still have a particular market share. Hence, the compatible platform will exist as a transitional solution before 2030 until the cost-effectiveness of PHEVs is lower than that of BEVs.

Thirdly, some new companies (Tesla Motors and NIO Motors, etc.) and companies with large technological reserves and production capacity (Volkswagen, Guangzhou Automobile Group (GAC), etc.) have developed new dedicated electric platforms before 2020 [48]. Before 2030, some traditional companies will develop compatible platforms and NDEPs at the same time. With the further rise of the BEV market, the advantages of the new dedicated electric platform are further highlighted. All the automotive companies will develop a new dedicated electric platform after 2030.

Fourthly, it was impossible to reduce the development cost of compatible platforms and new dedicated electric platforms through scale effects before NEVs had formed a market scale, especially the new dedicated electric platforms. The automotive companies would adapt the development model jointly developed to decrease the development cost. Automotive companies developing a new dedicated electric platform will share it with others actively because it can reduce the platform's development costs. Meanwhile, it will increase the visibility and influence of the enterprise platform. In turn, it can make the enterprise's platform development model become standard.

Finally, NEV platforms contain automotive product platforms and automotive architecture platforms [49]. Most of the current NEV platforms are automotive product platforms for developing serialized products. For example, the Tesla Model 3 automotive platform is a typical product platform. A new energy vehicle architecture platform is composed of several common modules that can be used and combined. That is a carrier of multiple different product platforms that uses a combination of various common modules. The architecture platform can also be referred to as a modular platform. For example, the VW MEB platform is a typical architecture platform.

Moreover, the new energy vehicle product platform needs to transition to a modular architecture platform in the future. The degree of generalization and sharing of parts of the product platform is lower. The powerful companies have transitioned from a product platform to an architecture platform such as the TNGA architecture platform of Toyota Motors [50]. Architecture platforms can use modularity to break the differences between product platforms so that components and modules between product platforms can be shared on a larger scale [20]. The new energy vehicle architecture platform will play a more significant role in reducing costs and increasing efficiency for automotive companies in the future.

\section{Conclusions}

This study aimed to investigate the automotive platform selection strategies and development models for automotive companies. First, we researched the significance of developing new energy vehicle platforms. These sections mainly aimed to analyze and improve the existing literature.

Second, we classified new energy vehicle platforms and judged their development trends. Compatible platforms and new dedicated electric platforms are the leading solutions for automotive companies. Compatible platforms can consider the development of multiple powertrains but cannot achieve the best performance of BEVs. With the government's policy support and the increase in the market share of BEVs, a new dedicated electric platform would develop faster.

Third, we revealed new energy vehicle platform selection strategies and development models for different automotive companies. Automotive companies should comprehensively consider their external and internal factors when choosing NEV platform development strategies. External factors affect the development trend of the NEV platform, while internal factors determine the specific choice of the enterprise. At the same time, compa- 
nies should choose platform development models based on their brand, scale, technical reserves, and corporate positioning. As competition in the new energy vehicle market intensifies, the development of NEV platforms will show a trend of joint development and shared use in the future. It can reduce development costs and investment risks for companies. Moreover, companies should increase their research and development efforts on new energy vehicle architecture platforms to maximize platform-based development's scale effect and application value.

Author Contributions: Conceptualization, Z.L. and F.Z.; data curation, X.L.; formal analysis, X.L.; funding acquisition, Z.L. and F.Z.; methodology, Z.L. and X.L.; project administration, Z.L.; supervision, F.Z.; validation, F.Z.; visualization, F.Z.; writing-original draft, X.L.; writing-review and editing, Z.L. All authors have read and agreed to the published version of the manuscript.

Funding: This research was funded by the National Natural Science Foundation of China, grant numbers U1764265, 71774100, 71690241.

Acknowledgments: The authors would like to thank the anonymous reviewers for their reviews and comments.

Conflicts of Interest: The authors declare no conflict of interest.

\section{References}

1. Chen, J.M. Carbon neutrality: Toward a sustainable future. Innovation 2021, 2, 100127. [CrossRef]

2. Hu, S.; Yang, J.; Jiang, Z.; Ma, M.; Cai, W. $\mathrm{CO}_{2}$ Emission and Energy Consumption from Automobile Industry in China: Decomposition and Analyses of Driving Forces. Processes 2021, 9, 810. [CrossRef]

3. Zhao, J.; Xi, X.; Na, Q.; Wang, S.; Kadry, S.N.; Kumar, P.M. The technological innovation of hybrid and plug-in electric vehicles for environment carbon pollution control. Environ. Impact Assess. Rev. 2021, 86, 106506. [CrossRef]

4. Qiao, Q.; Zhao, F.; Liu, Z.; Hao, H.; He, X.; Przesmitzki, S.V.; Amer, A.A. Life cycle cost and GHG emission benefits of electric vehicles in China. Transp. Res. Part D: Transp. Environ. 2020, 86, 102418. [CrossRef]

5. Karki, A.; Phuyal, S.; Tuladhar, D.; Basnet, S.; Shrestha, B.P. Status of Pure Electric Vehicle Power Train Technology and Future Prospects. Appl. Syst. Innov. 2020, 3, 35. [CrossRef]

6. China Association of Automobile Manufacturers. New Energy Vehicle Production and Sales Continue to Break New Records in July 2021. Available online: http://www.caam.org.cn/chn/4/cate_154/con_5234371.html (accessed on 1 August 2021).

7. IEA. Global EV Outlook 2021; IEA: Paris, France, 2021. Available online: https://www.iea.org/reports/global-ev-outlook-2021 (accessed on 25 September 2021).

8. Zhang, X.; Rao, R.; Xie, J.; Liang, Y. The Current Dilemma and Future Path of China's Electric Vehicles. Sustainability 2014, 6, 1567-1593. [CrossRef]

9. Du, J.; Ouyang, D. Progress of Chinese electric vehicles industrialization in 2015: A review. Appl. Energy 2017, 188, 529-546. [CrossRef]

10. Berckmans, G.; Messagie, M.; Smekens, J.; Omar, N.; Vanhaverbeke, L. Cost Projection of State of the Art Lithium-Ion Batteries for Electric Vehicles Up to 2030. Energies 2017, 10, 1314. [CrossRef]

11. An, J.; Mikhaylov, A.; Richter, U.H. Trade war effects: Evidence from sectors of energy and resources in Africa. Heliyon 2020, 6, e05693. [CrossRef] [PubMed]

12. Morkovkin, D.E.; Gibadullin, A.A.; Kolosova, E.V.; Semkina, N.S.; Fasehzoda, I.S. Modern transformation of the production base in the conditions of Industry 4.0: Problems and prospects. J. Phys. Conf. Ser. 2020, 1515, 032014. [CrossRef]

13. An, J.; Mikhaylov, A.; Jung, S.-U. A Linear Programming approach for robust network revenue management in the airline industry. J. Air Transp. Manag. 2021, 91, 101979. [CrossRef]

14. Fellini, R.; Kokkolaras, M.; Michelena, N.; Papalambros, P.; Saitou, K.; Perez-Duarte, A.; Fenyes, P. A sensitivity-based commonality strategy for family products of mild variation, with application to automotive body structures. Struct. Multidiscip. Optim. 2004, 27, 89-96. [CrossRef]

15. Robertson, D.; Ulrich, K. Planning for product platforms. Sloan Manag. Rev. 1998, 39, 19.

16. Paralikas, J.; Fysikopoulos, A.; Pandremenos, J.; Chryssolouris, G. Product modularity and assembly systems: An automotive case study. CIRP Ann. 2011, 60, 165-168. [CrossRef]

17. Skold, M.; Karlsson, C. Product platform development in industrial networks. Int. J. Automot. Technol. Manag. 2011, 11, 040868. [CrossRef]

18. Muffatto, M. Introducing a platform strategy in product development. Int. J. Prod. Econ. 1999, 60, 145-153. [CrossRef]

19. Hodges, P. Issues in Automotive Product Platform Strategies; SAE Technical Paper 2004-01-0483; SAE: Warrendale, PA, USA, 2004. [CrossRef]

20. Zhao, F.; Liu, Z.; Li, Z. Automotive Product Platform Modular Development Mode and Implementation Strategy. Automob. Technol. 2017, 6, 1-6. 
21. Siddique, Z.; Rosen, D.W.; Wang, N. On the applicability of product variety design concepts to automotive platform commonality. In Proceedings of the DETCí98: 1998 ASME Design Engineering Technical Conferences, Atlanta, GA, USA, 13-16 September 1998.

22. Muniz, S.T.G.; Belzowski, B.M. Platforms to enhance electric vehicles' competitiveness. Int. J. Automot. Technol. Manag. 2017, 17, 151-168. [CrossRef]

23. Liu, Z.; Hao, H.; Cheng, X.; Zhao, F. Critical issues of energy efficient and new energy vehicles development in China. Energy Policy 2018, 115, 92-97. [CrossRef]

24. Liu, X.; Zhao, F.; Hao, H.; Chen, K.; Liu, Z.; Babiker, H.; Amer, A.A. From NEDC to WLTP Effect on the Energy Consumption, NEV credits, and Subsidies Policies of PHEV in the Chinese Market. Sustainability 2020, 12, 5747. [CrossRef]

25. Liu, F.; Mauzerall, D.L.; Zhao, F.; Hao, H. Deployment of fuel cell vehicles in China: Greenhouse gas emission reductions from converting the heavy-duty truck fleet from diesel and natural gas to hydrogen. Int. J. Hydrog. Energy 2021, 46, 17982-17997. [CrossRef]

26. NIDEC Corporation. EV Platform, Future Technologies. Available online: https://www.nidec.com/en/technology/new_field/ ev-platform/ (accessed on 24 September 2021).

27. Ford. Deutsche Bank Conference. 2015. Available online: https://corporate.ford.com/content/dam/corporate/en/investors/ investor-events /Conferences/2015/2015-deutsche-bank-conference.pdf (accessed on 16 January 2016).

28. Electric Vehicle Platforms, Automotive IQ Guides. Available online: https:/ /www.automotive-iq.com/electrics-electronics/ articles / automotive-iq-guides-electric-vehicle-platforms (accessed on 10 June 2019).

29. Diffner, B.; Björkman, M.; Johansen, K. Successful Automotive Platform Strategy-Key Factors. In Proceedings of the 4th International Swedish Production Symposium, Lund, Sweden, 3-5 May 2011; pp. 85-92.

30. Gu, Y.; Hu, W.; Chen, J. Development Requirement and Implementation Strategy of Electric Vehicle Chassis Platform. Automob. Pract. Technol. 2020, 12, 32-34.

31. Top Five: Global EV Platforms. Automotive IQ Guides. Available online: https://www.automotive-iq.com/chassis-systems/ articles / top-five-global-ev-platforms (accessed on 18 July 2020).

32. GEP 2.0 New Deddicated Electric Platform. 2021. Available online: https://news.yiche.com/hao/wenzhang/50945452/ (accessed on 11 August 2021).

33. Volkswagen Group Modular Electric Drive Matrix (MEB) Platform. Available online: https:/ /www.volkswagen-newsroom.com/ en/modular-electric-drive-matrix-meb-3677 (accessed on 24 September 2021).

34. JLR Reveals Details of Future MLA Architecture. Available online: https://www.electrive.com/2019/06/23/jlr-reveals-detailsof-future-mla-architecture/ (accessed on 23 June 2019).

35. UMTRI. Carmakers Electric Vehicle's Stratgies: Platforms, Making and Charging. 2016. Available online: https:/ /pdf4pro.com/ view / carmakers-electric-vehicles-strategies-platforms-5bc060.html (accessed on 6 March 2016).

36. Kang, H.; Li, Y. Research on Development Strategy of xEV Compatible Architecture Platform. Shanghai Automob. 2019, 7, 11-18. Available online: https:/ / www.cnki.com.cn/Article/CJFDTotal-SHQC201907003.htm (accessed on 25 September 2021).

37. BMWBLOG. BMW CLAR Platform to Get Important Update in 2021. Available online: https://www.bmwblog.com/2020/01/06 /bmw-clar-platform-to-get-important-update-in-2021/ (accessed on 6 January 2020).

38. Lin, J.; Yao, K. Discussion on Development Strategy of Vehicle Architecture under Intelligent Network Interconnection. Shanghai Automot. 2019, 12, 11-14.

39. Wang, R.; Sell, R.; Rassolkin, A.; Otto, T.; Malayjerdi, E. Intelligent functions development on autonomous electric vehicle platform. J. Mach. Eng. 2020, 20, 114-125. [CrossRef]

40. Wang, Y.; Zhao, F.; Yuan, Y.; Hao, H.; Liu, Z. Analysis of Typical Automakers' Strategies for Meeting the Dual-Credit Regulations Regarding CAFC and NEVs. Automot. Innov. 2018, 1, 15-23. [CrossRef]

41. He, X.; Ou, S.; Gan, Y.; Lu, Z.; Przesmitzki, S.V.; Bouchard, J.L.; Sui, L.; Amer, A.A.; Lin, Z.; Yu, R.; et al. Greenhouse gas consequences of the China dual credit policy. Nat. Commun. 2020, 11, 5212. [CrossRef] [PubMed]

42. Automotive News. JLR Axed Electric Land Rover, Jaguar on MLA Platform to Focus on Better Tech. 2021. Available online: https:/ / www.autonews.com/cars-concepts/jlr-axed-electric-land-rover-jaguar-mla-platform-focus-better-tech (accessed on 2 March 2021).

43. Bailey, D. How Long Can Jaguar Land Rover Continue to Go It alone? 2019. Available online: http:/ / www.open-access.bcu.ac. uk/11067/1/How\%20long\%20can\%20Jaguar\%20Land\%20Rover\%20continue\%20to\%20go\%20it\%20alone.pdf (accessed on 25 June 2020).

44. Toyota and Tesla to Jointly Develop EV Platform? Available online: https://www.motorauthority.com/news/1131773_toyotaand-tesla-to-jointly-develop-ev-platform (accessed on 1 April 2021).

45. Ford, Volkswagen Sign Agreements for Joint Projects on Commercial Vehicles, EVs, Autonomous Driving. Available online: https:/ / media.ford.com/content/fordmedia/feu/en/news/2020/06/10/Ford-Volkswagen-Sign-Agreements.html (accessed on 10 June 2020).

46. Brylawski, M. Uncommon Knowledge: Automotive Platform Sharing's Potential Impact on Advanced Technologies. Available online: https://rmi.org/wp-content/uploads/2017/05/RMI_Document_Repository_Public-Reprts_T99-10_UncommonKnwldg. pdf (accessed on 21 July 2019).

47. SAE-China. Technology Roadmap for Energy Saving and New Energy Vehicles 2.0; China Machine Press: Beijing, China, 2020. 
48. A Complete Guide to Every Car Brand's Electric Vehicle Platforms. Available online: https://www.gearpatrol.com/cars/g35832 149/electric-vehicle-platforms / (accessed on 22 March 2021).

49. Yang, G. Research on Development Strategy of Vehicle Architecture Oriented to Modularization. Shanghai Automob. 2013, 10, 49-52.

50. Toyato. Making Ever-Better Cars. Available online: https://global.toyota/en/mobility/tnga/ (accessed on 24 September 2021). 